\title{
Article \\ Effect of Microstructure on the Onset Strain and Rate per Strain of Deformation-Induced Martensite Transformation in Q\&P Steel by Modeling
}

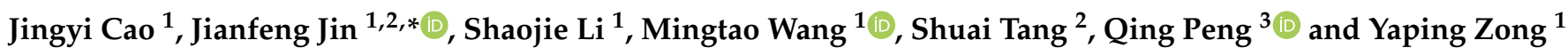 \\ 1 School of Materials Science and Engineering, Northeastern University, Shenyang 110819, China; \\ neu_caojy@163.com (J.C.); lisj_neu@163.com (S.L.); wangmingtao@mail.neu.edu.cn (M.W.); \\ ypzong@mail.neu.edu.cn (Y.Z.) \\ 2 State Key Laboratory of Rolling and Automation, Northeastern University, Shenyang 110819, China; \\ tangshuai@ral.neu.edu.cn \\ 3 State Key Laboratory of Nonlinear Mechanics, Institute of Mechanics, Chinese Academy of Sciences, \\ Beijing 100190, China; pengqing@imech.ac.cn \\ * Correspondence: jinjf@atm.neu.edu.cn
}

Citation: Cao, J.; Jin, J.; Li, S.; Wang, M.; Tang, S.; Peng, Q.; Zong, Y. Effect of Microstructure on the Onset Strain and Rate per Strain of DeformationInduced Martensite Transformation in Q\&P Steel by Modeling. Materials 2022, 15, 952. https://doi.org/ $10.3390 / \mathrm{ma} 15030952$

Academic Editor: Andrea Di Schino

Received: 31 December 2021

Accepted: 23 January 2022

Published: 26 January 2022

Publisher's Note: MDPI stays neutral with regard to jurisdictional claims in published maps and institutional affiliations.

Copyright: () 2022 by the authors Licensee MDPI, Basel, Switzerland. This article is an open access article distributed under the terms and conditions of the Creative Commons Attribution (CC BY) license (https:// creativecommons.org/licenses/by/ $4.0 /)$.

\begin{abstract}
The effect of microstructure on the onset strain and rate of deformation-induced martensitic transformation (DIMT) in Q\&P steel is studied by a mean-field micromechanics model, in which the residual austenite $(R A)$ and primary martensite $(M)$ phases are treated as elastoplastic particles embedded into the ferrite $(F)$ matrix. The results show that when the volume fraction of the $R A$ increases with a constant fraction of the $M$, the onset strain of DIMT increases and transformation rate decreases, in contrast to the case of the $R A$ fraction effect with a fixed $F$ fraction. Increasing the volume fraction of the $M$ postpones the DIMT, regardless of the corresponding change from the $R A$ or $F$ fraction, which is similar to the effect of the $R A$ fraction with the constant $M$ but to a higher degree. Conversely, when increasing the fraction of the matrix $F$, the onset strain of DIMT increases and the rate decreases, and the effect is greater when the corresponding fraction change comes from the $M$ rather than from the $R A$. Moreover, when the aspect ratio of the $R A$ increases, the onset strain of DIMT decreases with a gradual increase in transformation rate, in agreement with the experimental observation that the equiaxial austenite is more stable in Q\&P steels. However, the aspect ratio effect of the $M$ is opposite to that of the $R A$, indicating that the lath-shaped primary martensite could protect the austenite from DIMT.
\end{abstract}

Keywords: deformation-induced martensitic transformation; microstructure; onset strain of phase transformation; Q\&P steel; micromechanics model

\section{Introduction}

As one of the typical advanced high-strength steels (AHSSs), quenching and partitioning $(\mathrm{Q} \& \mathrm{P})$ steel can be used in vehicle light-weighting, energy saving, and emission reduction due to its excellent strength and ductility [1]. After quenching and partitioning processing, Q\&P steel has a complex microstructure composed of ferrite, residual austenite, and martensite [2]. Mechanical behaviors of Q\&P steel are significantly affected by the residual austenite phase due to deformation-induced martensite transformation (DIMT). As the steel for automobile components, the occurrence of DIMT in Q\&P steel can greatly improve driving safety by absorbing more kinetic energy during impacting [3]. Therefore, understanding the effect of microstructure on the DIMT in Q\&P steel is essential to control the occurrence of DIMT in service.

In multiphase steels, the residual austenite is observed in different morphologies, such as blocky, film-like, or inter-lath lamellar shapes [4-6]. Each morphology has its own characteristics in the DIMT. During deformation, the blocky austenite grain usually has 
a low transformation stability [4], the lamellar-shaped one has intermediate stability, and the film-like austenite shows the highest stability against the DIMT [5]. Moreover, it is reported that the lamellar austenite grain with a larger aspect ratio is less stable than one with a smaller ratio [6]. In addition, plastic deformation behaviors of the surrounding phases of the austenite have also been reported to affect its transformation stability $[7,8]$. Therefore, the stability of residual austenite depends not only on its own characteristics, but also on the microstructural features such as the shape and content of other phases in Q\&P steel. Furthermore, during hot forming of martensitic stainless steels, this microstructure effect on the features of DIMT is also important to optimize processing parameters and mechanical properties of the steels [9].

In order to understand and manipulate the DIMT in multiphase steels, the effects of microstructural factors on the DIMT need to be clarified, in which the accurate stress and strain partitioning in the residual phase is required. In some works [10-14], the effects of the DIMT features on deformation behaviors of multiphase steels can be studied by modeling. For instance, the macroscopic behaviors of multiphase TRIP steel were predicted and the effects of phase composition and morphology on flow stress and strain hardening were studied from a physical-based model [15], in which the results showed that the much harder martensite phase gives rise to a strong hardening of the residual austenite islands. In the works $[11,16,17]$, the stress and strain partitioning between different phases in multiphase TRIP steel was evaluated using a mean-field homogenization model and the results indicated that the optimum strength-ductility balance could be achieved by an intermediate stable austenite, where too rapid transformation of austenite led to a lack of hardening or too slow transformation could not provide the extra strain hardening required to postpone localization. Delannay et al. calculated the partitioning of strain between softer and harder constituents in a TRIP multiphase steel based on an elastoplastic MoriTanaka model, and the macroscopic stress-strain curves and rate of martensite formation subjected to various loading were predicted [12], indicating that the accommodation of the transformation strain had a negligible effect on macroscopic stress when the fraction of residual austenite was low. Moreover, two- and three-dimensional microstructure-based representative volume element models are also used to study the mechanical response of multiphase steels [18-21]. Choi et al. developed a microstructure-based finite element (FE) model and studied the failure mode of multiphase TRIP steel containing residual austenite with DIMT [18]. In [19], the effects of phase properties on strength and ductility in Q\&P steel were examined by an FE model and it was found that when the stability and/or volume fraction of residual austenite were higher and the phase strength difference was less, the higher phase-hardening benefited Q\&P steels. Srivastava et al. studied the effect of stress partitioning among phases on mechanical behaviors in Q\&P980 steel [22], using a microstructure-based finite element model. However, few works focus on the onset of DIMT, which is critical for controlling DIMT in service.

In this work, using a mean-field micromechanics model $[23,24]$, regarding residual austenite and primary martensite phases as the elastoplastic particulate reinforcements embedded into the ferrite matrix, the microstructural effect on onset strain and rate of deformation-induced martensitic transformation (DIMT) in Q\&P steel is quantitively studied and compared, aiming to facilitate the development of AHSSs.

\section{Micromechanics Model for Multiphase Q\&P Steel}

\subsection{Modeling of Multiphase QEP Steel}

In this work, the material sample is commercial Q\&P980 sheet steel as received from Baosteel in China with ultimate tensile strength of $980 \mathrm{MPa}$ and thickness of $1.2 \mathrm{~mm}[19,25]$. The chemical composition is listed in Table 1 and the microstructure contains ferrite, primary martensite, and residual austenite phases with volume fractions of $37 \%, 52 \%$, and $11 \%$, respectively, as shown in Figure 1a. 
Table 1. Chemical composition of the samples of Q\&P980 steel ( $w \mathrm{t} \%)$.

\begin{tabular}{ccccccc}
\hline Element Type & $\mathbf{C}$ & Mn & Si & P & S & Al \\
\hline Content & 0.2 & 1.93 & 1.59 & 0.019 & 0.003 & 0.055 \\
\hline
\end{tabular}

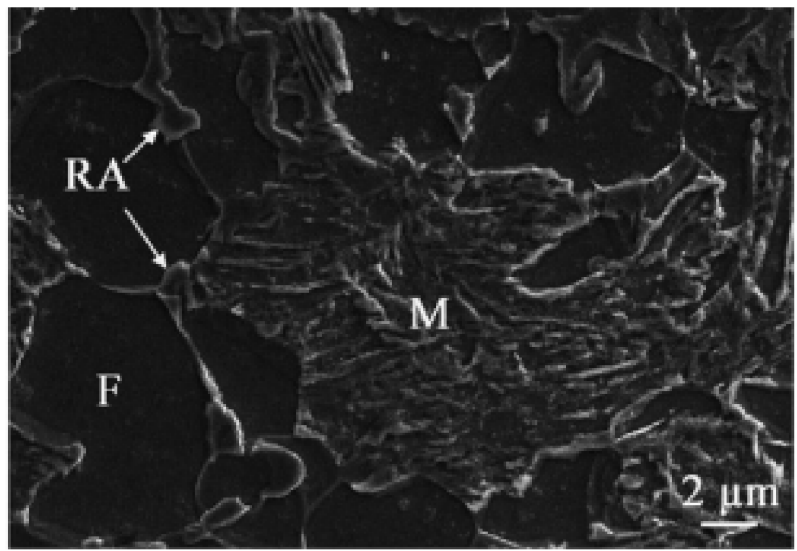

(a)

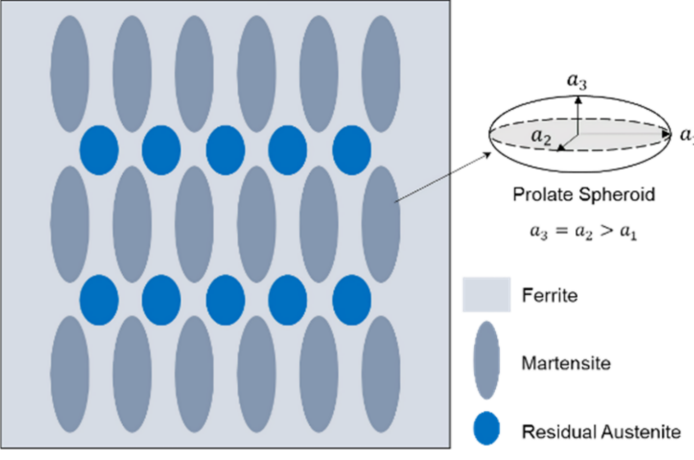

(b)

Figure 1. Microstructure of Q\&P steel (a) from scanning electron microscopy [25] and (b) schematics of the mean-field micromechanics model setup.

Based on an Eshelby model, a micromechanics model was established in our previous work to simulate the onset strain of DIMT in Q\&P980 steel [24]. The model setup is schematically shown in Figure $1 \mathrm{~b}$. The assumptions in the micromechanics model are as follows: (1) the ferrite $(F)$ was taken as the matrix, the residual austenite $(R A)$ and martensite $(M)$ were taken as the 1st and 2nd inhomogeneities, embedded in the ferrite matrix, (2) the averaged shapes of martensite and residual austenite are treated as prolate spheroids with aspect ratios $s\left(=a_{3} / a_{1}\right)$ of 3 and 1.2, respectively, and (3) the matrix-inhomogeneity interfaces are perfectly bonded.

In this work, the model was originally based on Eshelby's equivalent inclusion approach [16] with the unique equation expressed as $C_{I}\left(e^{C}-e^{T *}\right)=C_{m}\left(e^{C}-e^{T}\right)$ [23], where $e^{C}, e^{T *}$, and $e^{T}$ are the constrained strain, mismatch strain, and imagined strain, respectively, $e^{C}=S e^{T}$ ( $S$ is Eshelby tensor), and $C_{I}$, and $C_{m}$ are the stiffness of inclusion (i.e., particle) and matrix, respectively. The equation built a relationship between the matrix and inclusions into a continuum mechanics framework. After combining the Mori-Tanaka mean-field method [17], a micromechanics model was developed and the stress in inclusions in a finite matrix was calculated by $\sigma_{I}=\sigma_{m}+C_{m}\left(e^{0}+e_{I}^{C}-e_{I}^{T}\right)+C_{m}\left(\bar{e}+e_{I}^{C}-e_{I}^{T}\right)$ [23], where $\sigma_{m}$ is the matrix stress, $e^{0}$ is a far-field strain of the matrix, and $\bar{e}$ is the interactive strain in the matrix. The advantage of the Eshelby-based mean-field model is that the perturbation effect of inhomogeneities embedded in the matrix is considered and background stress in the matrix is introduced to account for the disturbance of the matrix elastic strain fields surrounding the inhomogeneities neighboring each other in a finite, non-diluted system, namely, the mean strain within the matrix from the elastic stress field of homogeneous and heterogeneous materials is discrepant. More details about the model were described in previous works $[23,24]$ and this work focuses on the analysis of the simulation results and potential applications in the steel industry.

\subsection{Constitutive Inputs of Each Phase}

The elastic modulus of ferrite, residual austenite, and primary martensite are $220 \mathrm{GPa}$, $187 \mathrm{GPa}$, and $187 \mathrm{GPa}$, respectively, and Poisson's ratio of each phase is $0.3[12,13]$. The experimental stress-strain curves $[12,18,20]$ were used as the constitutive inputs to describe elastoplastic responses of the individual phases of residual austenite and primary martensite, which were validated in our previous work [24]. After comparing the experimental 
stress-strain curves of the single-phase ferrite steels in a tensile test [18-21] in Figure 2a, the constitutive input [19] is chosen as the input of the matrix ferrite phase, due to a similar chemical composition of the experimental Q\&P980 sample used in this work.

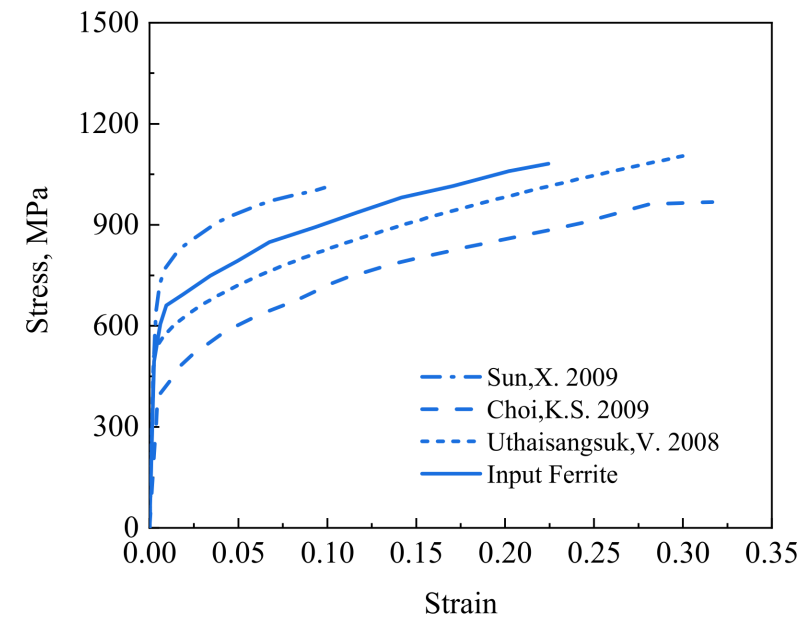

(a)

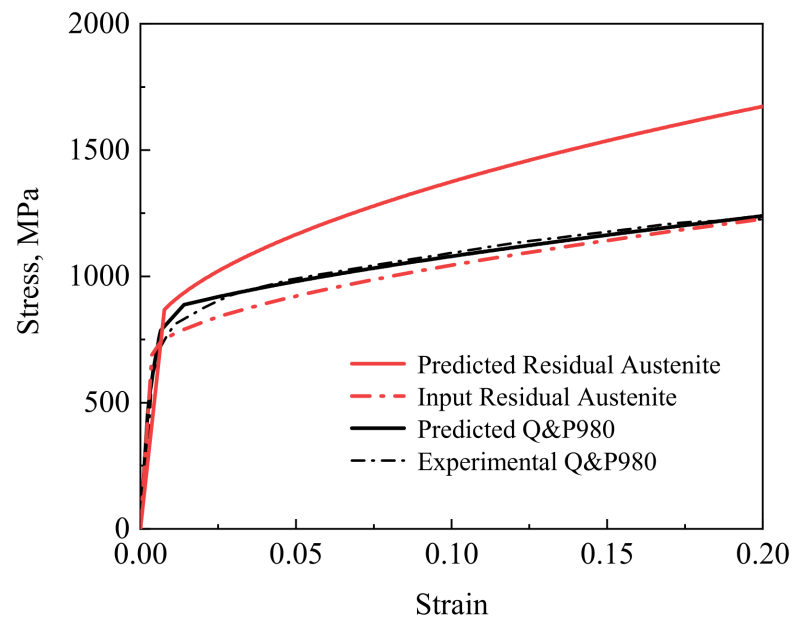

(b)

Figure 2. (a) Comparison of the experimental stress-strain curves of the single-phase ferrite steels [18-21] for choosing the input stress of the ferrite phase in the model of Q\&P980 steel and (b) the predicted stress of Q\&P980 steel and the stress partitioning in the residual austenite phase, in comparison to the experimental results of Q\&P980 steel during a tensile test [25] and the constitutive input stress of residual austenite phase [24].

The macroscopic stress-strain curve predicted by the micromechanics model is shown in Figure 2b, and is in good agreement with the experimental one of Q\&P980 steel during a tensile test [25]. The difference between the predicted and input stress of the residual austenite represents the load bearing in multiphase Q\&P980 steel, which indicates that the model can be attainable to study the DIMT characteristics based on the austenite stress partitioning above.

\section{Results and Discussion}

\subsection{Prediction of Onset Strain and Tranformation Rate of DIMT in QEP980 Steel under Uniaxial Loading}

In our previous work [24], it was indicated that the onset strain of DIMT can be determined by a stress criterion of martensite transformation as a function of the applied strain. The calculated critical stress of the onset of the martensite transformation was about $985 \mathrm{MPa}$ [24] and the onset strain of DIMT $\left(\varepsilon_{\text {onset }}\right)$ was the corresponding applied strain in the predicted stress-strain curve of residual austenite when the stress $\left(\sigma_{R A}\right)$ was equal to $985 \mathrm{MPa}$. Since the stress partitioning of residual austenite varies with microstructure, the effects of the microstructure of the Q\&P steel on onset strain of DIMT can be examined by the micromechanics model under a far-field applied strain.

In order to calculate the transformation rate of the DIMT, based on the experimental results of Q\&P steels [25-27], the transformation proportion of DIMT $\left(f_{\mathrm{DIMT}}=f_{N B} / f_{R A}\right)$ is fitted out as a function of applied strain in Figure 3,

$$
f_{\operatorname{DIMT}}(\varepsilon)=27.6 e^{2.4 \varepsilon}-45.2 e^{-30.4 \varepsilon}
$$

where $f_{N B}$ and $f_{R A}$ are the volume fraction of newborn martensite from DIMT and original residual austenite, respectively. Here, it is assumed that there is no microstructural effect on the stress criterion of martensite transformation. 


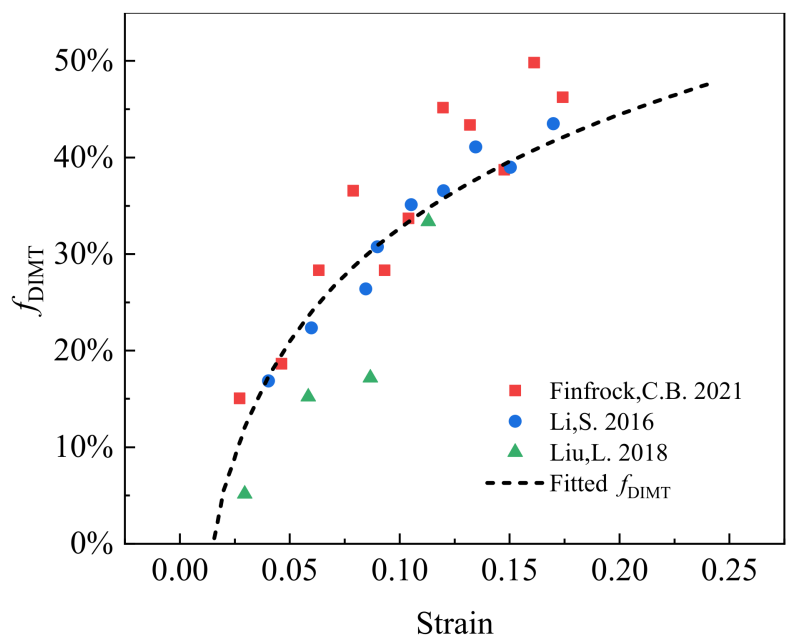

Figure 3. The transformation proportion of deformation-induced martensite transformation (DIMT) $\left(f_{\text {DIMT }}=f_{N B} / f_{R A}\right)$ during straining from the experiments in Q\&P steels [25-27], where $f_{N B}$ and $f_{R A}$ are volume fraction of the newborn martensite and initial residual austenite, respectively.

Combining the predicted stress-strain curve of the $R A$ in Figure $2 b$ with Equation (1), we can deduce a relationship between $f_{\text {DIMT }}$ and the stress in residual austenite $\left(\sigma_{R A}\right)$ as

$$
f_{\text {DIMT }}\left(\sigma_{R A}(\varepsilon)\right)=1.33 \times\left(\sigma_{R A}-985\right)^{0.54}
$$

In this work, the rate per strain of DIMT is presented by the $f_{\text {DIMT }}$ at the applied strain of $15 \%$.

\subsection{Volume Fraction Effect of Each Constitutive Phase on Onset Strain and Rate of DIMT during Tensile Loading}

In this section, the volume fraction effect of each constitutive phase on the onset strain $\left(\varepsilon_{\text {onset }}\right)$ and rate of DIMT ( $f_{\text {DIMT }}$ at an applied strain of $15 \%$ ) during tensile loading is predicted, where the change in volume fraction is in the range of $2 \sim 41 \%$ for residual austenite $(R A), 32 \sim 62 \%$ for primary martensite $(M)$, and $17 \sim 47 \%$ for ferrite phase $(F)$.

Figure 4 illustrates the effect of the volume fraction of residual austenite $\left(f_{R A}\right)$ on onset strain and rate of DIMT, where the volume fractions of martensite $\left(f_{M}\right)$ and ferrite $\left(f_{F}\right)$ are fixed separately. When the $f_{R A}$ increases from $2 \%$ to $41 \%$ with $f_{M}$ of $52 \%$, the $\varepsilon_{\text {onset }}$ increases from $2.1 \%$ to $2.5 \%$ and $f_{\text {DIMT }}$ decreases from $39.8 \%$ to $38.2 \%$, as shown in Figure 4 a, while in the case of the RA fraction effect with constant $f_{F}$ of $37 \%$ in Figure $4 \mathrm{~b}$, there is a sharp

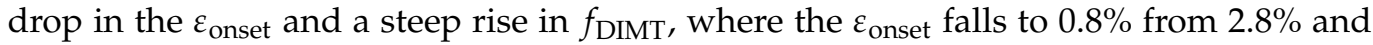
the $f_{\text {DIMT }}$ rises to a high point at $46.1 \%$ from $37.3 \%$ with $f_{R A}$ from $2 \%$ to $41 \%$. The results suggest that as the $R A$ proportion increases, mechanical stability of the $R A$ becomes higher when the ferrite matrix decreases, while it becomes less stable when the harder primary martensite decreases.

Figure 5 shows the effect of the volume fraction of martensite $\left(f_{M}\right)$ on onset strain and rate of DIMT, corresponding to the change in $f_{R A}$ or $f_{F}$, respectively. When the $f_{M}$ increases from $32 \%$ to $62 \%$ with a constant $f_{R A}$ of $11 \%$, the $\varepsilon_{\text {onset }}$ increases from $1.0 \%$ to $2.9 \%$ and $f_{\text {DIMT }}$ decreases from $44.8 \%$ to $36.9 \%$, as shown in Figure 5 a. When the $f_{M}$ increases from $32 \%$ to $62 \%$ with a constant $f_{F}$ of $37 \%$ in Figure $5 b$, the $\varepsilon_{\text {onset }}$ rises to $2.8 \%$ from $1.2 \%$ and the $f_{\text {DIMT }}$ falls to a low point at $37.3 \%$ from $43.8 \%$. The results suggest that as the $M$ proportion increases, mechanical stability of the $R A$ becomes higher regardless the corresponding change from the $R A$ or $F$ fraction. 


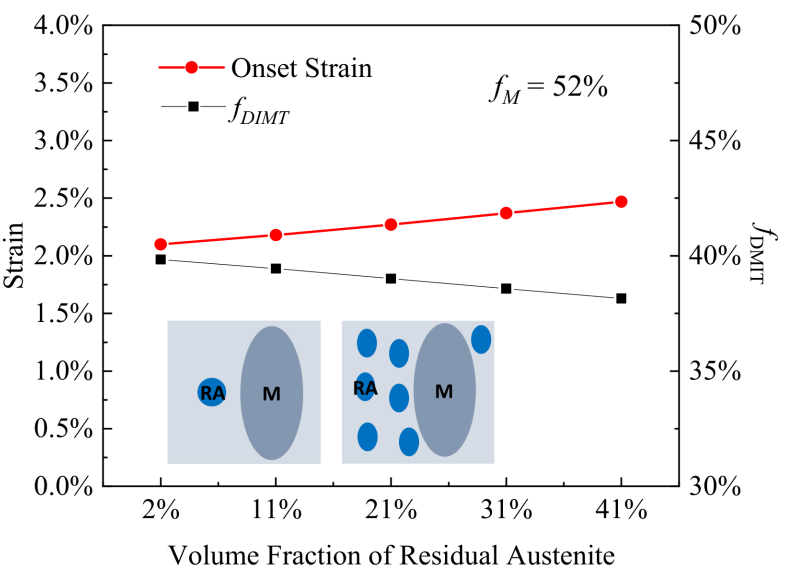

(a)

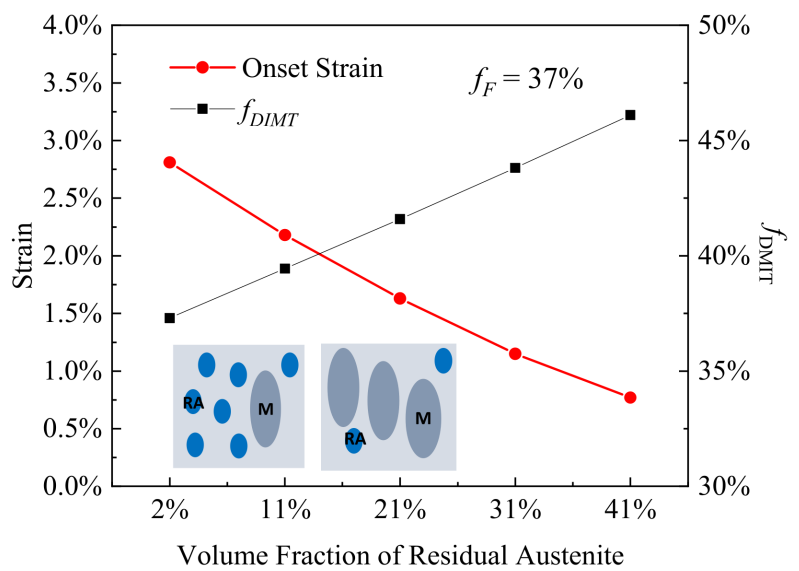

(b)

Figure 4. The onset strain and transformation rate of DIMT ( $f_{D I M T}$ at the applied strain of $\left.15 \%\right)$ during straining as a function of volume fraction of residual austenite (a) with the fixed volume fraction of primary martensite $\left(f_{M}\right)$ of $52 \%$ and $(\mathbf{b})$ with the fixed volume fraction of ferrite $\left(f_{F}\right)$ of $37 \%$, where the blue is remarked as the residual austenite and the dark gray is primary martensite within the insets.

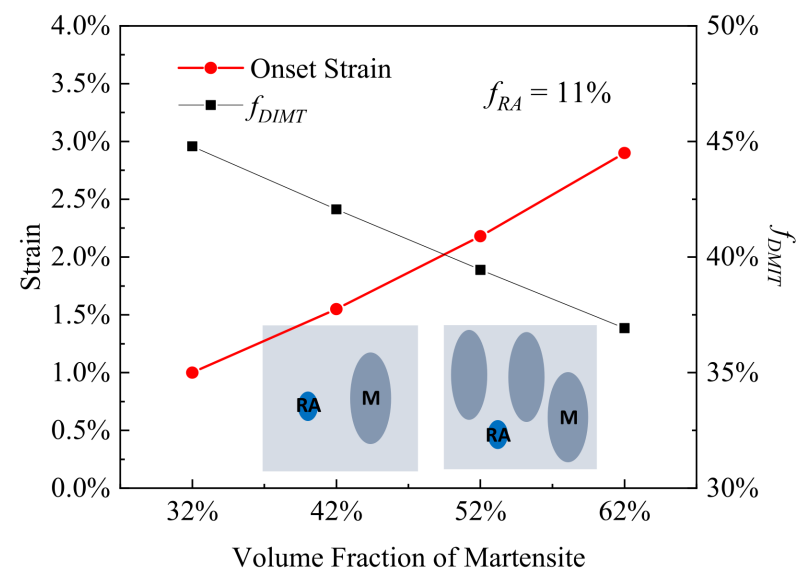

(a)

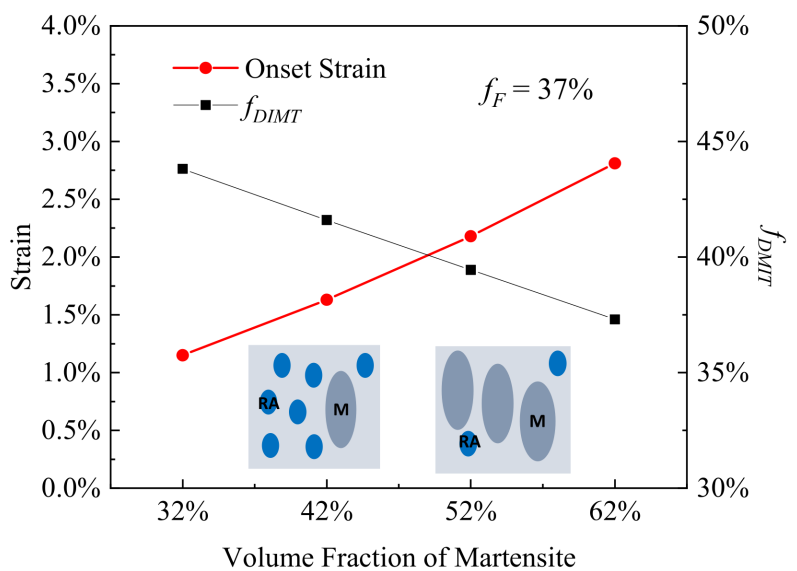

(b)

Figure 5. The onset strain and transformation rate of DIMT ( $f_{D I M T}$ at the applied strain of $\left.15 \%\right)$ during straining as a function of volume fraction of primary martensite (a) with the fixed volume fraction of residual austenite $\left(f_{R A}\right)$ of $11 \%$ and $(\mathbf{b})$ with the fixed volume fraction of ferrite $\left(f_{F}\right)$ of $37 \%$, where the blue is remarked as the residual austenite and the dark gray is primary martensite within the insets.

Figure 6 presents the effect of the $f_{F}$ on onset strain and rate of DIMT, where the $f_{M}$ and $f_{R A}$ are fixed separately. When the $f_{F}$ increases from $17 \%$ to $47 \%$ with a constant $f_{M}$ of $52 \%$, the $\varepsilon_{\text {onset }}$ decreases from $2.4 \%$ to $2.1 \%$ and $f_{\text {DIMT }}$ increases from $38.6 \%$ to $39.8 \%$, as in Figure $6 \mathrm{a}$. In Figure $6 \mathrm{~b}$, the $\varepsilon_{\text {onset }}$ falls to $1.6 \%$ from $3.7 \%$ and the $f_{\text {DIMT }}$ rises to a high value at $42.1 \%$ from $34.5 \%$, when the $f_{F}$ is from $17 \%$ to $47 \%$ with a constant $f_{R A}$ of $11 \%$. The results suggest that as the $F$ proportion increases, mechanical stability of the $R A$ becomes lower, associated with the decrease in $R A$. A similar but more significant effect of the $F$ fraction is observed when the corresponding $M$ fraction decreases. 


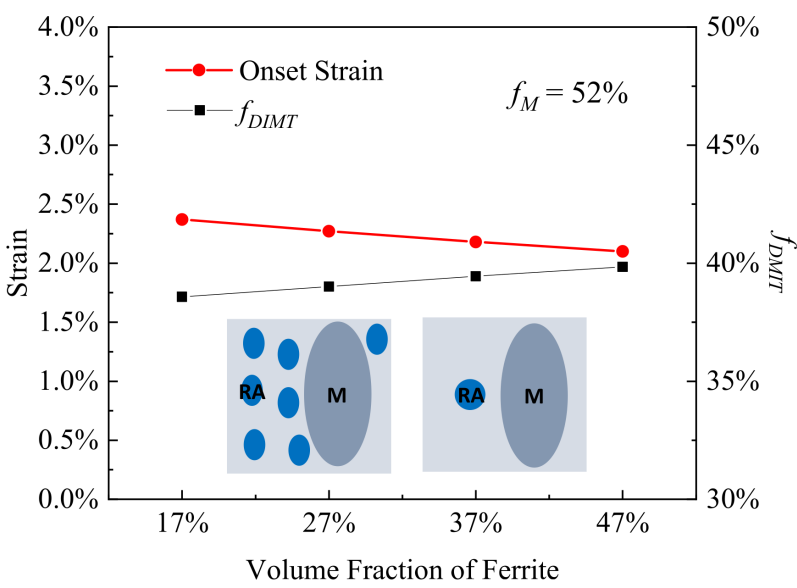

(a)

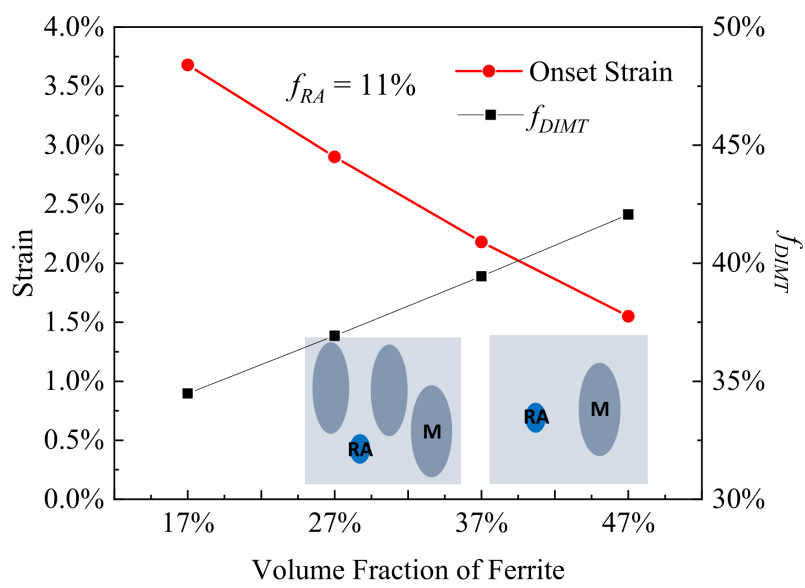

(b)

Figure 6. The onset strain and transformation rate of DIMT ( $f_{D I M T}$ at the applied strain of $15 \%$ ) during straining as a function of volume fraction of ferrite (a) with the fixed volume fraction of primary martensite $\left(f_{M}\right)$ of $52 \%$ and (b) with the fixed volume fraction of residual austenite $\left(f_{R A}\right)$ of $11 \%$, where the blue is remarked as the residual austenite and the dark gray is primary martensite within the insets.

3.3. Aspect Ratio Effect of Particle-Shaped Residual Austenite and Primary Martensite on Onset Strain and Rate of DIMT during Tensile Loading

In this section, the onset strain and rate of DIMT are calculated and compared with different aspect ratios of the residual austenite $(R A)$ and primary martensite $(M)$ of Q\&P steel, respectively.

In Figure 7, the effect of the $R A$ aspect ratio along the tensile direction on the $\varepsilon_{\text {onset }}$ and $f_{\text {DIMT }}$ is studied, with a constant $M$ aspect ratio of 3.0. The $\varepsilon_{\text {onset }}$ decreases from $3.5 \%$ to $2.4 \%$ and the $f_{\text {DIMT }}$ decreases from $34.5 \%$ to $38.7 \%$, when the $R A$ aspect ratio changes from $1 / 9$ to 1 in Figure $7 \mathrm{a}$. The $\varepsilon_{\text {onset }}$ further decreases from $2.4 \%$ to $1.1 \%$ and the $f_{\text {DIMT }}$ increases from $38.7 \%$ to $45.1 \%$ when the RA aspect ratio varies from 1 to 9 in Figure $7 \mathrm{~b}$. The results indicate when the aspect ratio of the $R A$ increases, the onset strain of DIMT decreases with a gradual increase in transformation rate, in agreement with the experimental observation that the equiaxial austenite is more stable in Q\&P steels [6].

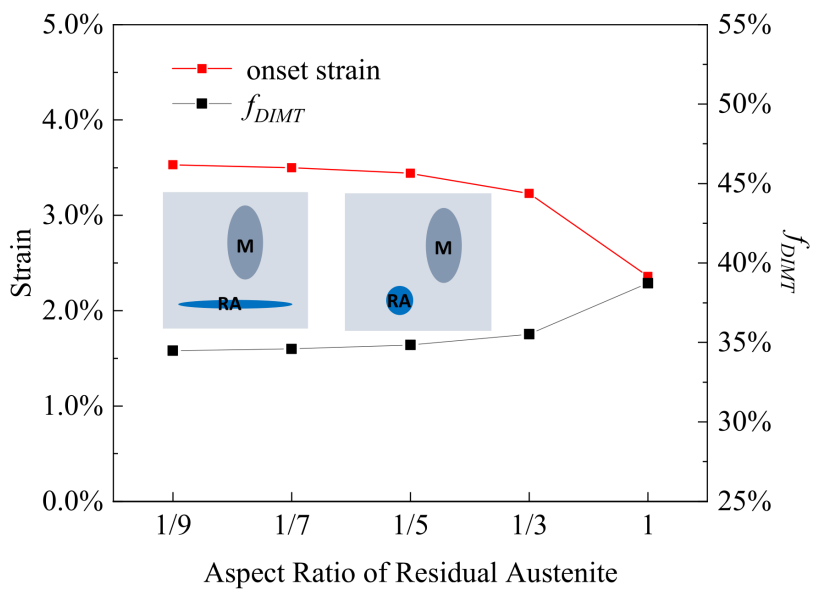

(a)

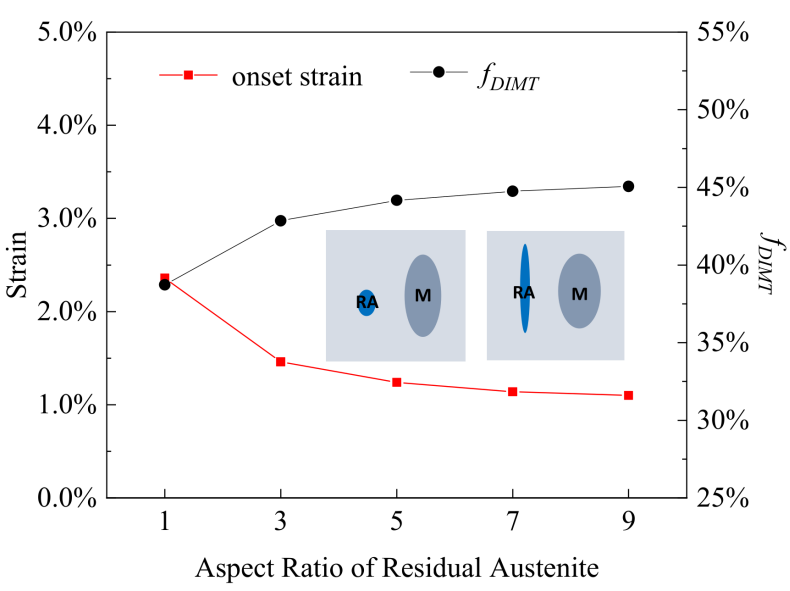

(b)

Figure 7. The onset strain and transformation rate of DIMT ( $f_{\text {DIMT }}$ at the applied strain of $15 \%$ ) during straining as a function of aspect ratio of residual austenite with the aspect ratio (a) from 1/9 to 1 and (b) from 1 to 9 , where the blue is remarked as the residual austenite and the dark gray is primary martensite within the insets. 
Figure 8 shows the effect of the $M$ aspect ratio on the $\varepsilon_{\text {onset }}$ and $f_{\text {DIMT }}$, with the $R A$ aspect ratio being 1.2. In Figure 8 a, the $\varepsilon_{\text {onset }}$ increases from $0.3 \%$ to $0.7 \%$ and $f_{\text {DIMT }}$ decreases from $53.1 \%$ to $47.2 \%$ when the $M$ aspect ratio changes from $1 / 9$ to 1 . Figure $8 \mathrm{~b}$ shows that the $\varepsilon_{\text {onset }}$ increases from $0.7 \%$ to $4.1 \%$ and the $f_{\text {DIMT }}$ decreases from $47.2 \%$ to $34.1 \%$ when the $M$ aspect ratio further changes from 1 to 9 . The results indicate that the aspect ratio effect of the $M$ is opposite to that of the $R A$ and the lath-shaped primary martensite could protect the residual austenite from DIMT.

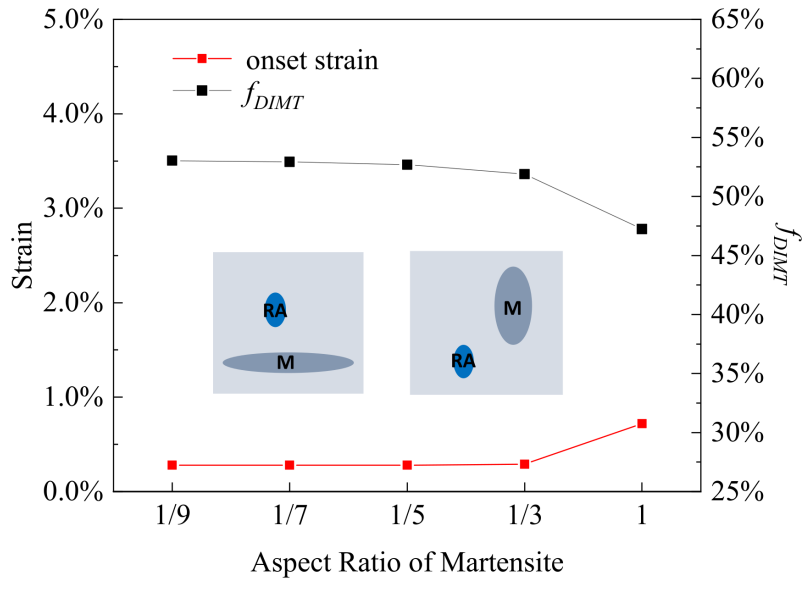

(a)

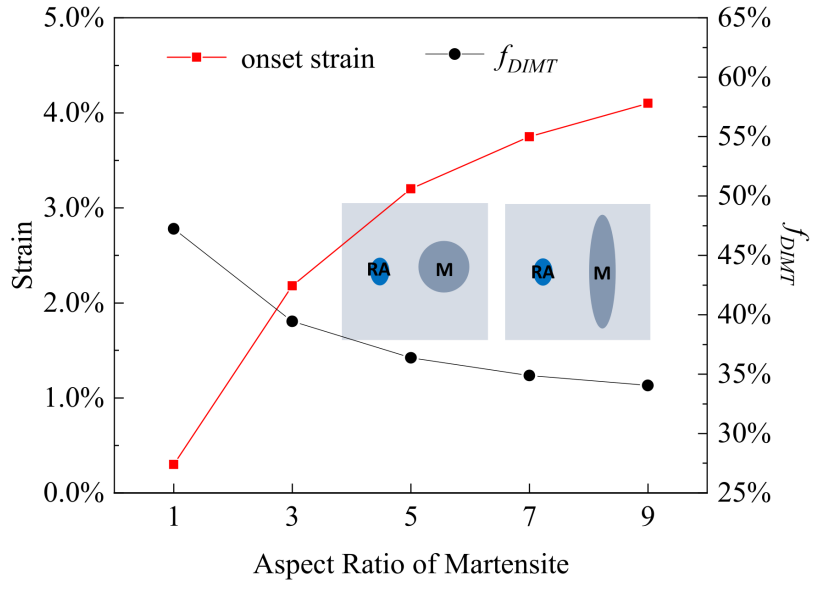

(b)

Figure 8. The onset strain and transformation rate of DIMT ( $f_{D I M T}$ at the applied strain of $\left.15 \%\right)$ during straining as a function of the aspect ratio of primary martensite with the aspect ratio (a) from $1 / 9$ to 1 and (b) from 1 to 9 , where the blue is remarked as the residual austenite and the dark gray is primary martensite within the insets.

\subsection{Applications of the Modeling Results in Controlling DIMT of QEP Steel}

The results above give better understanding on the effects of microstructural factors on DIMT in Q\&P steel, which can provide some guidance to design the chemical composition, optimize processing parameters, and improve in-service performance. For instance, since the increase in the $R A$ fraction may be attributed to an increase in the carbon content in Q\&P steel [28], the effect of carbon content on DIMT can be related to the findings in Figure 4. According to the experimental observations in the process of Q\&P steel [29,30], increasing quenching temperature may lead to a decrease in the martensite proportion, in which the volume fraction of martensite in a medium-carbon Q\&P steel decreased from $80 \%$ to $26 \%$ with quenching temperature (QT) from 200 to $320^{\circ} \mathrm{C}$ [29], while the martensite fraction in a low-carbon Q\&P steel decreased from $82 \%$ to $36 \%$ within the same range of QT [30]. In additional, the average carbon content of the residual austenite appeared to be almost independent of QT. Therefore, the results in Figure 5 could facilitate the understanding of the effect of quenching temperature on DIMT in Q\&P steel. Moreover, it is also suggested that inputting different constitutive relationships of the phase into the micromechanics model may represent the characteristics of the phase, such as alloying [28] or loading conditions [31] in Q\&P steel, so more benefits can be achieved through further modeling efforts.

\section{Conclusions}

1. Microstructure effect on onset strain and transformation rate of deformation-induced martensitic transformation (DIMT) in Q\&P steel can be quantitatively studied through a micromechanics model.

2. When the volume fraction of residual austenite $(R A)$ increases from $2 \%$ to $41 \%$ with the martensite fraction of $52 \%$, the onset strain of DIMT increases from $2.1 \%$ to $2.5 \%$ 
and transformation rate decreases from $39.8 \%$ to $38.2 \%$, in contrast to the case of the $R A$ fraction effect with the constant fraction of ferrite.

3. With the volume fraction of the primary martensite $(M)$ increasing from $32 \%$ to $62 \%$, the DIMT can be postponed, regardless of the corresponding change from the $R A$ or $F$ fraction, where the onset strain of DIMT increases from $1.0 \%$ to $2.9 \%$ (with a constant fraction of $R A\left(f_{R A}=11 \%\right)$ or from $1.2 \%$ to $2.8 \%\left(f_{F}=37 \%\right)$, and the transformation rate decreases from $44.8 \%$ to $36.9 \%\left(f_{R A}=11 \%\right)$ or from $43.8 \%$ to $37.3 \%\left(f_{F}=37 \%\right)$.

4. When increasing the volume fraction of the matrix ferrite from $17 \%$ to $47 \%$, the onset strain of DIMT decreases from $2.4 \%$ to $2.1 \%\left(f_{M}=52 \%\right)$ or from $3.7 \%$ to $1.6 \%$ $\left(f_{R A}=11 \%\right)$ and the transformation rate increases from $38.6 \%$ to $39.8 \%\left(f_{M}=52 \%\right)$ or from $34.5 \%$ to $42.1 \%\left(f_{R A}=11 \%\right)$.

5. When the aspect ratio of the residual austenite increases from $1 / 9$ to 9 , the onset strain of DIMT decreases from $3.5 \%$ to $1.1 \%$ and transformation rate increases from $34.5 \%$ to $45.1 \%$.

6. When the aspect ratio of the primary martensite increases from $1 / 9$ to 9 , the onset strain of DIMT increases from $0.3 \%$ to $4.1 \%$ and transformation rate decreases from $53.1 \%$ to $34.1 \%$.

Author Contributions: Conceptualization, J.C., Y.Z. and J.J.; methodology, Y.Z., J.J. and S.L.; validation, J.C., S.L., J.J., M.W. and S.T.; formal analysis, J.C., J.J., S.T., Q.P. and Y.Z.; investigation, J.C., J.J., S.T. and Q.P.; resources, J.J. and S.T.; data curation, J.C. and S.L.; writing-original draft preparation, J.C. and S.L.; writing—review and editing, J.C., J.J., M.W., S.T., Q.P. and Y.Z.; visualization, J.C., J.J. and S.L.; supervision, J.J., S.T. and Y.Z.; project administration, J.J. and Y.Z.; funding acquisition, J.J., S.T. and Y.Z. All authors have read and agreed to the published version of the manuscript.

Funding: This research was funded by Fundamental Research Funds for the Central Universities (No. N2007011), National Natural Science Foundation of China (No.52175293) and Project of Introducing Talents of Discipline to Universities ("111" Project) (No. B20029).

Institutional Review Board Statement: Not applicable.

Informed Consent Statement: Not applicable.

Data Availability Statement: Not applicable.

Conflicts of Interest: The authors declare no conflict of interest.

\section{References}

1. Kwon, O.; Lee, K.Y.; Kim, G.S.; Chin, K.G. New Trends in Advanced High Strength Steel Developments for Automotive Application. Mater. Sci. Forum. 2010, 638-642, 136-141. [CrossRef]

2. Edmonds, D.V.; He, K.; Rizzo, F.C.; De Cooman, B.C.; Matlock, D.K.; Speer, J.G. Quenching and Partitioning Martensite-A Novel Steel Heat Treatment. Mater. Sci. Eng. A 2006, 438-440, 25-34. [CrossRef]

3. Mates, S.; Abu-Farha, F. Dynamic Tensile Behavior of a Quenched and Partitioned High Strength Steel Using a Kolsky Bar; Springer: Cham, Switzerland, 2016. [CrossRef]

4. Blondé, R.; Jimenez-Melero, E.; Zhao, L.; Wright, J.P.; Brück, E.; van der Zwaag, S.; van Dijk, N.H. Mechanical Stability of Individual Austenite Grains in TRIP Steel Studied by Synchrotron X-ray Diffraction during Tensile Loading. Mater. Sci. Eng. A 2014, 618, 280-287. [CrossRef]

5. Mark, A.F.L. Microstructural Effects on The Stability of Retained Austenite in Transformation Induced Plasticity Steels; Queen's University: Kingston, ON, Canada, 2008.

6. De Knijf, D.; Föjer, C.; Kestens, L.A.I.; Petrov, R. Factors Influencing the Austenite Stability During Tensile Testing of Quenching and Partitioning Steel Determined via In-situ Electron Backscatter Diffraction. Mater. Sci. Eng. A 2015, 638, 219-227. [CrossRef]

7. Jacques, P.J.; Ladriere, J.; Delannay, F. On the Influence of Interactions Between Phases on the Mechanical Stability of Retained Austenite in Transformation-Induced Plasticity Multiphase Steels. Metall. Mater. Trans. A 2001, 32, 2759-2768. [CrossRef]

8. Chiang, J.; Lawrence, B.; Boyd, J.D.; Pilkey, A.K. Effect of Microstructure on Retained Austenite Stability and Work Hardening of TRIP Steels. Mater. Sci. Eng. A 2011, 528, 4516-4521. [CrossRef]

9. Derazkola, H.A.; Gil, E.G.; Murillo-Marrodán, A.; Méresse, D. Review on Dynamic Recrystallization of Martensitic Stainless Steels during Hot Deformation: Part I-Experimental Study. Metals 2021, 11, 572. [CrossRef]

10. Dan, W.J.; Zhang, W.G.; Li, S.H.; Lin, Z.Q. A Model for Strain-Induced Martensitic Transformation of TRIP Steel with Strain Rate. Comput. Mater. Sci. 2007, 40, 101-107. [CrossRef] 
11. Lani, F.; Furnémont, Q.; Van Rompaey, T.; Delannay, F.; Jacques, P.J.; Pardoen, T. Multiscale Mechanics of TRIP-Assisted Multiphase Steels: II. Micromechanical Modelling. Acta Mater. 2007, 55, 3695-3705. [CrossRef]

12. Delannay, L.; Jacques, P.; Pardoen, T. Modelling of the Plastic Flow of Trip-Aided Multiphase Steel Based on an Incremental Mean-field Approach. Int. J. Solids Struct. 2008, 45, 1825-1843. [CrossRef]

13. Sierra, R.; Nemes, J.A. Investigation of The Mechanical Behaviour of Multi-Phase TRIP Steels Using Finite Element Methods. Int. J. Mech. Sci. 2008, 50, 649-665. [CrossRef]

14. Han, H.N.; Oh, C.-S.; Kim, G.; Kwon, O. Design Method for TRIP-aided Multiphase Steel Based on a Microstructure-based Modelling for Transformation-induced Plasticity and Mechanically Induced Martensitic Transformation. Mater. Sci. Eng. A 2009, 499, 462-468. [CrossRef]

15. Perlade, A.; Bouaziz, O.; Furnémont, Q. A Physically Based Model for TRIP-Aided Carbon Steels Behaviour. Mater. Sci. Eng. A 2003, 356, 145-152. [CrossRef]

16. Eshelby, J.D. The Determination of the Elastic Field of an Ellipsoidal Inclusion, and Related Problems. Proc. R. Soc. Lond. Ser. A 1957, 241, 376-396. [CrossRef]

17. Mori, T.; Tanaka, K. Average Stress in Matrix and Average Elastic Energy of Materials with Misfitting Inclusions. Acta Metall. 1973, 21, 571-574. [CrossRef]

18. Choi, K.S.; Liu, W.N.; Sun, X.; Khaleel, M.A. Microstructure-Based Constitutive Modeling of TRIP Steel: Prediction of Ductility and Failure Modes under Different Loading Conditions. Acta Mater. 2009, 57, 2592-2604. [CrossRef]

19. Cheng, G.; Choi, K.S.; Hu, X.H.; Sun, X. Computational Material Design for Q\&P Steels with Plastic Instability Theory. Mater. Des. 2017, 132, 526-538. [CrossRef]

20. Sun, X.; Choi, K.S.; Liu, W.N.; Khaleel, M.A. Predicting Failure Modes and Ductility of Dual Phase Steels Using Plastic Strain Localization. Int. J. Plast. 2009, 25, 1888-1909. [CrossRef]

21. Uthaisangsuk, V.; Prahl, U.; Bleck, W. Micromechanical Modelling of Damage Behaviour of Multiphase Steels. Comput. Mater. Sci. 2008, 43, 27-35. [CrossRef]

22. Srivastava, A.; Ghassemi-Armaki, H.; Sung, H.; Chen, P.; Kumar, S.; Bower, A.F. Micromechanics of Plastic Deformation and Phase Transformation in a Three-Phase TRIP-Assisted Advanced High Strength Steel: Experiments and Modeling. J. Mech. Phys. Solids. 2015, 78, 46-69. [CrossRef]

23. Zong, B.Y.; Wang, Y.M.; Li, J.; Xu, N. Modeling of Mechanical Behavior and Design of Microstructure on Particulate Reinforced Materials. Int. J. Mod. Phys. B. 2009, 23, 1627-1633. [CrossRef]

24. Cao, J.; Jin, J.; Wang, L.; Li, S.; Zong, Y. Modeling for Onset Strain of Deformation-Induced Martensite Transformation in Q\&P Steel by a Mean-field Eshelby Approach. Modell. Simul. Mater. Sci. Eng. 2019, 27, 085002. [CrossRef]

25. Li, S.; Zou, D.; Xia, C.; He, J. Effect of Strain Rate on Deformation-Induced Martensitic Transformation of Quenching and Partitioning Steels. Steel Res. Int. 2016, 87, 1302-1311. [CrossRef]

26. Liu, L.; He, B.B.; Cheng, G.J.; Yen, H.W.; Huang, M.X. Optimum Properties of Quenching and Partitioning Steels Achieved by Balancing Fraction and Stability of Retained Austenite. Scr. Mater. 2018, 150, 1-6. [CrossRef]

27. Finfrock, C.B.; Thrun, M.M.; Bhattacharya, D.; Ballard, T.J.; Clarke, A.J.; Clarke, K.D. Strain Rate Dependent Ductility and Strain Hardening in Q\&P Steels. Metall. Mater. Trans. A 2021, 52, 928-942. [CrossRef]

28. Kähkönen, J. Quenching and Partitioning Response of Carbon-Manganese-Silicon Sheet Steels Containing Nickel, Molybdenum, Aluminum and Copper Additions. Ph.D. Thesis, Colorado School of Mines, Golden, CO, USA, 2016.

29. Matlock, D.K.; Bräutigam, V.E.; Speer, J.G. Appliacation of the Quenching and Partitioning (Q\&P) Process to a Medium-Carbon, High-Si Microalloyed Bar steel. Mater. Sci. Forum. 2003, 426-432, 1089-1094. [CrossRef]

30. Santofimia, M.J.; Zhao, L.; Petrov, R.; Kwakernaak, C.; Sloof, W.G.; Sietsma, J. Microstructural Development during the Quenching and Partitioning Process in a Newly Designed Low-Carbon Steel. Acta Mater. 2011, 59, 6059-6068. [CrossRef]

31. Wang, M.; Huang, M.X. Abnormal TRIP Effect on the Work Hardening Behavior of a Quenching and Partitioning Steel at High Strain Rate. Acta Mater. 2020, 188, 551-559. [CrossRef] 